\title{
Catalytic Ozonation: An Advanced Strategy for the Removal of Nitro Phenols from Contaminated Water
}

\section{Shanthi $\mathbf{S}^{*}$}

Department of Chemical Technology, Laxminarayan Institute of Technology, RTM Nagpur University, Nagpur, Maharashtra, India

\begin{abstract}
Novel advanced oxidation processes (AOPs) show extraordinary potential for application in numerous waste water treatment. This research work provides a solution for the removal of nitro phenols a common water pollutant. All studies were done in batch mode in a constantly stirred reactor. Reactant ozonation can be viewed, firstly as homogeneous photo-catalytic ozonation, which depends on ozone activation by metal particles present in solution, and secondly as heterogeneous catalytic ozonation using Granular Activated Carbon (GAC). The present study reveals that $\mathrm{Cr}^{3+}, \mathrm{Co}^{2+}, \mathrm{Ce}^{4+}$ and $\mathrm{Cu}^{2+}$ ions favour the ozonation of nitro phenols by increasing the rate of ozonation and a much higher degradation of substrates was obtained in a given time. In case of heterogeneous catalytic ozonation using GAC catalyst, it was found that initially pollutants were adsorbed as the solution concentration decreased significantly within 5 minutes of contact. The maximum percentage reduction of the substrate was achieved in minimum possible time when catalysis was employed. The catalysts $\mathrm{Co}^{2+}$ and GAC gave the best results with respect to time and percentage degradation.
\end{abstract}

Keywords: Ozonation; Homogeneous catalysis; Heterogeneous catalysis; Granular activated carbon

\section{Introduction}

Numerous physical, natural and combination procedures are utilized for wastewater treatment. In any case, a few contaminants found in wastewater are stubborn to some degree to regularly used procedures. The circumstances are exacerbated by the need, or deficiency, of sufficient water treatment frameworks fit for reducing the centralization of poisonous substances. The incapability of conventional wastewater treatment methods to effectively remove many such nonbiodegradable and hazardous pollutants makes it imperative that new efficient treatment methods be developed [1,2]. It can be said that inadequately treated wastewaters lead to a deterioration of the quality of water resources and hence, of drinking water. Catalytic ozonation was found to be effective for the removal of several organic compounds from drinking water and wastewater. However, these results were mainly restricted to laboratory scale investigation. This study attempts to generalize the use of catalytic ozonation to a scale that it can be used in day-to-day waste water treatment in domestic as well as industrial scale for water contaminated with phenols. This study throw light to the fact that nitro phenols can be removed from wastewater streams effectively by batch catalytic ozonation processes based on the laboratory scale studies conducted.

Ozonation and adsorption jointly offer solid synergetic consequences for the removal of numerous organic contaminants $[3,4]$. It is, likewise, proficient in decontaminating groundwater, leachate from a German household transfer site, and wastewater from propane oxide production as presented by the catalytic ozone oxidation process ECOCLEAR [5,6].

The catalytic ozonation process on Cact was found by Kaptijn in 1997 to have a low ozone requirement and to be significantly less influenced by disintegrated radical scroungers, such as, (bi) carbonates. The reaction fundamentally happens on the surface of the catalyst. The efficiency of catalytic ozonation was found not to be influenced by temperature up to $80^{\circ} \mathrm{C}$ [7]. It was additionally observed to be similarly powerful under both exceedingly acidic conditions (when $\mathrm{OH}^{\bullet}$ radicals are not formed) and under exceptionally alkaline conditions. This suggested not $\mathrm{OH}^{\cdot}$ radicals, but rather other exceedingly dynamic species, for example, $\mathrm{O}^{*}$ radicals framed on the surface of the catalyst. Jans and Hoigné exhibited distinctive results obtained for water at $\mathrm{pH}$ $>5$ [8]. Activated carbon accelerates the transformation of ozone with $\mathrm{OH} \cdot$ radical generation. The hydroxyl radicals formed are not bound to the surface of carbon. They diffuse faster to the aqueous phase making oxidation easier.

Activated carbon can therefore kickstart a radical-type chain reaction that transforms $\mathrm{O}_{3}$ into $\mathrm{OH}^{*}$ in the aqueous phase. Removal of nitrophenols by ozonation and adsorption are studied individually $[9,10]$. In this study, a combination of both is tried and laboratory scale standardization is achieved.

\section{Advanced oxidation}

Substrate oxidation using hydroxyl radicals is a proven oxidation method for the removal of refractory organics from waste water stream $[11,12]$. The radicals are created in the reactor itself using advanced oxidation techniques with the aid of oxidants like ozone, hydrogen peroxide and UV light. They should be produced on site, in a reactor where the radicals can contact the organics in the wastewater. According to APHA alarming amount of nitrophenols from pesticides comes to water streams. The adsorption onto activated carbon is broadly used as a part of wastewater treatment for control of colour and odour, in the expulsion of organic compounds such as trihalomethane precursors, chlorine and to remove toxic compounds [13].

Here Catalytic ozonation using $\mathrm{Cu}^{2+}, \mathrm{Co}^{2+}, \mathrm{Cr}^{2+}, \mathrm{Fe}^{2+}$ and $\mathrm{Ce}^{4+}$ as homogenous catalysts and granular activated carbon as heterogeneous

*Corresponding author: Shanthi S, Department of Chemical Technology, Laxminarayan Institute of Technology, RTM Nagpur University, Nagpur, Maharashtra, India, Tel: 0971553990954; E-mail: pshanthi555@gmail.com, shanthi.chemistryschool@gmail.com

Received April 09, 2017; Accepted April 14, 2017; Published April 15, 2017;

Citation: Shanthi S (2017) Catalytic Ozonation: An Advanced Strategy for the Removal of Nitro Phenols from Contaminated Water. J Adv Chem Eng 7: 168. doi: 10.4172/2090-4568.1000168

Copyright: (c) 2017 Shanthi S. This is an open-access article distributed under the terms of the Creative Commons Attribution License, which permits unrestricted use, distribution, and reproduction in any medium, provided the original author and source are credited. 
catalyst are studied as appropriate strategies for the treatment of wastewaters containing toxic or non-biodegradable compound nitro phenol in water bodies.

\section{Catalytic ozonation}

Elective ozonation method forms catalyzed by transition metals or granular activated carbon have been explored for decomposition of organics. Literature pertaining to catalytic ozonation can be subdivided as follows:

(i) Homogeneous catalytic ozonation - Activation of ozone by aqueous metals in presence of UV radiation

(ii) Heterogeneous catalytic ozonation Utilizing metal oxides/ metals on supports/granular activated carbon as catalysts.

Catalyzed ozonation may be a promising way to enhance the rate of oxidation [14]. The advantages offered by the use of an ozone-based catalytic system have been established for the removal of organic pollutants such as atrazine, chlorobenzenes, halocarbons [15-18]. Utilization of heterogeneous catalytic ozonation for the treatment of various industrial wastewaters has been reported [4]

\section{Heterogeneous catalysis}

Surface catalysis (heterogeneous catalysis) includes five sequential steps which impact the overall rate of the chemical conversion: (1) Diffusion of the reagents toward the catalyst, (2) The reagent - catalyst interaction (adsorption), (3) Reaction between the adsorbed reagents resulting into products, (4) Surface desorption of the product from the catalyst towards the medium, and (5) Products diffusing away from the catalyst. While the first and last steps correspond to physical processes of matter transfer, the intermediate steps consist of chemical phenomena, the reaction taking place between the chemically adsorbed species by arrangement of surface complexes. Clearly, adsorption just constitutes an initial phase in the chemical reaction. The catalyst, therefore, cannot be chosen only for its adsorbent capacity. More significantly, in order to widen the scope to a broad range of compounds; the adsorption must be limited to a physical adsorption through Vander Waals interactions. This physical adsorption permits the genuine chemical reaction started by the formation of covalent or ionic bonds between the catalyst surface and the adsorbed pollutant molecule. If too strong, this association can lead to catalyst poisoning. Also, irreversible adsorption of the reaction products will stop further reactions. Interestingly with physical adsorption, catalytic reaction is more particular and subsequently decides the general catalyst proficiency $[6,19]$.

\section{Homogeneous catalysis}

Another chance to quicken ozonation responses is to utilize homogeneous catalysts. A few metal ions $\left(\mathrm{Fe}^{2+}, \mathrm{Cd}^{2+}, \mathrm{Cu}^{2+}, \mathrm{Zn}^{2+}\right.$, $\mathrm{Co}^{2+}, \mathrm{Cr}^{2+}, \mathrm{Mn}^{2+}, \mathrm{Fe}^{3+}$, etc.,) have been examined and sometimes a noteworthy increasing speed in the disintegration of the target compound has been accomplished, in spite of the fact that the reaction mechanism in most cases remained vague. The use of transition metal ion as catalyst follows a mechanism, which depends on an ozone decomposition reaction thus generating hydroxyl radicals. The initiation step is the generation of $\mathrm{O}_{2}^{-*}$ radical by the ions present in the solution is achieved by UV activation. The transfer of an electron from $\mathrm{O}_{2} \cdot$-molecule to $\mathrm{O}_{3}$ causes the formation of $\mathrm{O}_{3}{ }^{-}$, and subsequently HO• $[20]$.

Cortes et al. considered advanced oxidation of chlorobenzenes in wastewater and additionally in model systems utilizing iron and manganese particles as heterogeneous catalysts [17].
As discussed before, activated carbon accelerates the ozonation process [21]. Hydroxyl radicals are thought to significantly affect the decomposition of ozone. The mechanism of catalytic ozone decomposition proposed by Beltrán et al. for GAC activated ozonation credits all the while to the heterogeneous ozone disintegration on the surfaces of the catalyst, and homogeneous responses take place in the aqueous solution [22].

The mechanism can be presented as follows:

1. Homogeneous decomposition:

$\begin{array}{lll}\mathrm{O}_{3}+\mathrm{OH}^{-} & \rightarrow & \mathrm{HO}_{2}^{-}+\mathrm{O}_{2} \\ \mathrm{O}_{3}+\mathrm{HO}_{2}^{-} & \rightarrow & \mathrm{HO}_{2}^{-}+\mathrm{O}_{3}^{--} \\ \mathrm{O}_{3}+\mathrm{In} & \rightarrow & \mathrm{O}_{3}^{\cdot-}+\mathrm{In}^{+} \\ \mathrm{HO}_{2}^{\cdot} & \leftrightarrow & \mathrm{O}_{2}^{--}+\mathrm{H}^{+}\end{array}$

2. Heterogeneous decomposition surface reaction:

$\begin{array}{lll}\mathrm{OH}^{-}+\mathrm{S} & \leftrightarrow & \mathrm{OH}-\mathrm{S} \\ \mathrm{O}_{3}+\mathrm{OH}-\mathrm{S} & \leftrightarrow & \mathrm{O}_{3}-\mathrm{S}+\mathrm{HO} \cdot \\ \mathrm{O}_{3}-\mathrm{S} & \leftrightarrow & \mathrm{O}^{-\mathrm{S}}+\mathrm{O}_{2} \\ \mathrm{O}_{3}+\cdot \mathrm{O}-\mathrm{S} & \leftrightarrow & \mathrm{O}_{2} \cdot-\mathrm{S}+\mathrm{O}_{2}\end{array}$

3. Homogeneous propagation and termination reactions:

$\begin{array}{lll}\mathrm{O}_{3}+\mathrm{O}_{2}^{--} & \rightarrow & \mathrm{O}_{3}^{\cdot-}+\mathrm{O}_{2} \\ \mathrm{O}_{3}^{\cdot-}+\mathrm{H}^{+} & \rightarrow & \mathrm{HO}_{3}^{\cdot} \\ \mathrm{HO}_{3}^{\cdot} & \rightarrow & \mathrm{HO}+\mathrm{O}_{2} \\ \mathrm{HO}_{3}^{\cdot}+\mathrm{P} & \rightarrow & \text { end products }\end{array}$

Where $S$ is the catalyst surface in the initiator of ozone decomposition and $\mathrm{P}$ is the scavenger of hydroxyl radicals.

Only reactions (5)-(8) are the steps of the surface chemical reaction involving adsorption, surface reactions and desorption process. They are followed by reactions (9)-(12) taking place in the aqueous phase. This backs Jans and Hoigné's outcomes concerning the direct formation of free radicals in aqueous phases [8]. As ozonation reactions happens faster in alkaline solutions, also in this case too, it was found that ozonation in presence of GAC is favoured in basic $\mathrm{pH}$. In summary, it is highlighted that basic Lewis sites are thought to be accountable for ozone breakdown on activated carbon.

Ozone-Granulated Activated Carbon systems $\left(\mathrm{O}_{3} / \mathrm{GAC}\right)$ are potential cases of catalytic ozonation [23]. The combined $\mathrm{O}_{3} / \mathrm{GAC}$ system is well acknowledged for non-biodegradable compounds destruction where the bed life of GAC column is prolonged due to the ozonated water [24]. However, the action of GAC as a catalyst for free radical's formation in ozonated water is not well studied and the reported results in literature are quite contradictory. Kaptijn explained the oxidation of bio refractory organics in the ozonation column filled with the GAC bed by the radicals such as $\mathrm{O}_{2}{ }^{--}, \mathrm{O}_{2}{ }^{--}$(not only by $\mathrm{HO}$ radicals) on the surface of GAC. This procedure has been in commercial operation since 1992 at an ozone consumption of $1.7 \mathrm{~kg}$ ozone per $1 \mathrm{~kg}$ COD expelled. Jans and Hoigne summarized that a radical-type chain reaction is initiated by a few milligrams of activated carbon or carbon black per litre in ozone-containing water. This then proceeds to the propagation step producing more $\mathrm{HO}^{\bullet}$ radicals in the aqueous phase. 


\section{Materials and Methods}

The substrates selected in the present study are classified as priority pollutants by environmental protection agencies around the world. Since their name occurs repeatedly in the text, these chemicals are given simple abbreviated names mentioned in the bracket.

\section{Nitrophenols (NP)}

- o-nitrophenol (ONP), m-nitrophenol (MNP) and p-nitrophenol (PNP)

According to Agency for Toxic Substances and Disease Registry, nitrophenols are synthetic pollutants [25]. They are a widespread synthetic component found in industrial effluents and have been recognized in urban and agricultural waste. NPs are intermediates formed during pesticide and dye manufacturing, and are found in rainwater as an after effect of the tropospheric conversion of alkyl benzenes. The ways by which they enter the environment varies from industrial effluents and spills to breakdown of specific pesticides containing NP moieties. This profound number of sources results in large quantities of NPs entering nature. NPs are known to uncouple oxidative phosphorylation and are in this way considered as priority contaminants [26]. NPs being stable compounds stay in deep soil and in groundwater for longer period without degradation.

\section{Devices}

The oxidation studies were carried out using following devices and equipment's

Ozone generator: A high frequency cold plasma/cold corona ozone generator supplied by M/s. Beta Computronics Private Limited, Nagpur, India was used to produce ozone. The unit comes consists of a built in air pump, ozone cells, step-up transformer, power supply and gas termination. High voltage is generated with a high quality ferrite core transformer. The ozone cells were fabricated from high-grade stainless steel. The ozone cells are air cooled by three heavy-duty fans so that the cell temperature is kept low to avoid ozone destruction. The dielectric used is $99.99 \%$ pure quartz glass. All the pipe terminations are machined out of stainless steel grade 316 , and piping is made of silicon/Teflon materials. The output of the ozone generator contained $61.13+/-0.5 \mathrm{mg} / \mathrm{l}$ ozone. The generator inlet was fed with $6.52+/-$ $0.01 \mathrm{l} / \mathrm{min}$ of air using an aerator. When oxygen was used instead of air for ozone production, instead of aerator, the ozone generator was connected to oxygen cylinder with an oxygen flow meter.

Ozone reactor without UV irradiation: Heterogeneous catalytic ozonation experiments were carried out in a 2 litre borosilicate bottle fitted with a standard joint having ozone feed and exit arrangement (Figure 1, reactor B). The ozone generated is directly fed to the reactor. The total volume of the substrate solution taken in the reactor was 750 $\mathrm{ml}$. Uniform stirring of the solution and distribution of ozone gas was ensured using a diffuser made up of non-reactive polymeric material. The exit gas from the reactor was fed to iodine wash bottles fitted in series.

UV Photo reactor: A magnetic stirrer equipped cylindrical batch photo reactor was utilized for homogeneous catalytic ozonation experiments (Figures 2 and 3, reactor A). The reactor was made of borosilicate glass. A quartz double walled immersion tube was placed inside the glass reactor, which was fitted with a standard joint. An 8-watt low-pressure mercury vapour lamp was placed inside the immersion well. The UV lamp (Philips make) supplied by Eureka Forbes Pvt. Ltd was used for the studies. This lamp emits around $87 \%$ UV rays at 254

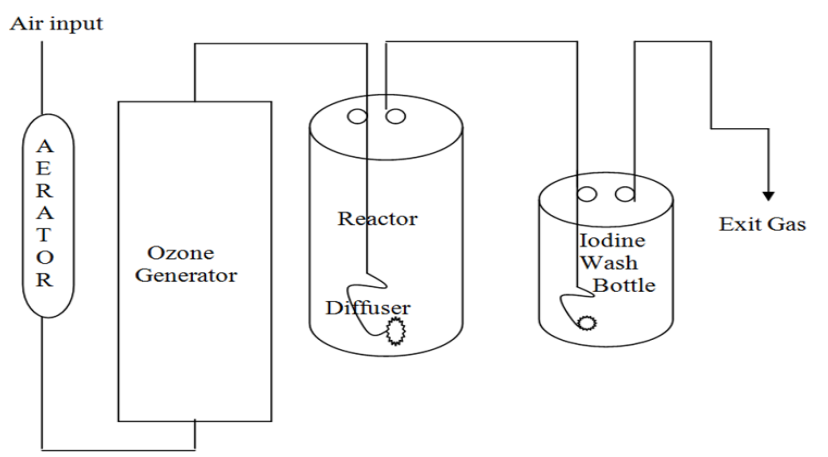

Figure 1: Ozonation Experimental setup flow chart - Reactor A.

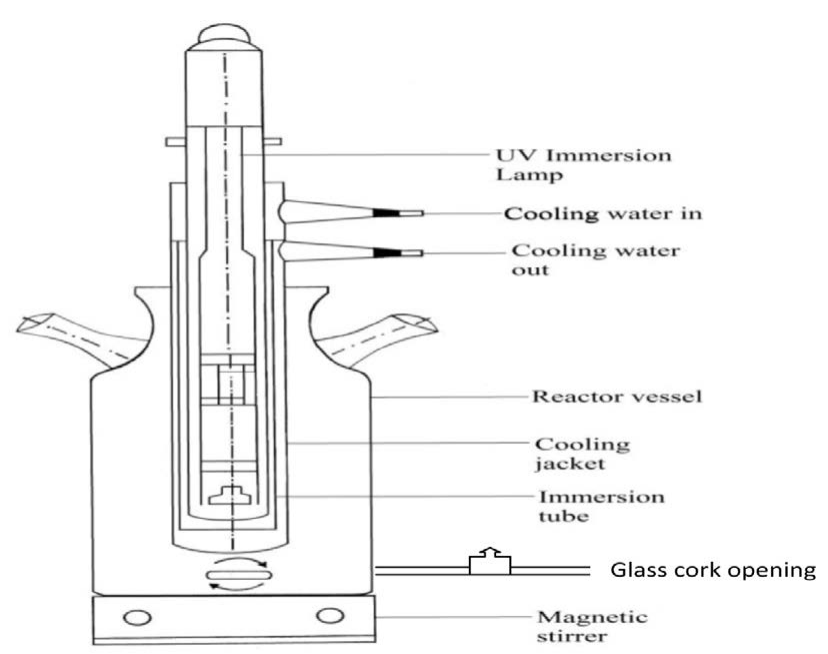

Figure 2: Photo reactor - Reactor B.

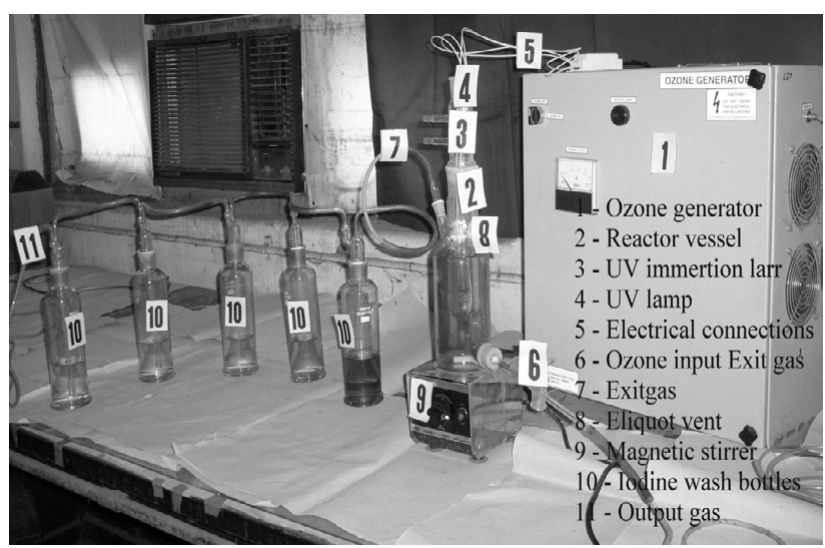

Figure 3: Experimental set up for UV assisted ozonation using reactor $B$.

nm (Figure 2) and about $98 \%$ of the rays at this wavelength can pass through quartz. The total volume of the photo reactor was $850 \mathrm{ml}$. Ozonation was achieved by bubbling the ozone gas through the glass stopper opening at the base of the reactor. A stirring effect was also created by the ozone gas bubbled from the base of the reactor. 


\section{Methodology}

Heterogeneous catalytic ozonation experiments were performed using $750 \mathrm{ml}$ of $0.0005 \mathrm{M}$ aqueous solution of the nitro phenol taken in Reactor- $\mathrm{B}$. The beginning of heterogeneous catalytic ozonation using GAC as catalyst corresponds to direct addition of GAC catalyst to the nitrophenol solution and simultaneous start of ozone gas bubbling. Effective gas liquid mass transfer was achieved by using a polymeric ozone diffuser. Care has been taken to avoid plugging of the diffuser by suspended solids, catalyst particles and oxidised precipitates.

Homogeneous catalytic ozonation using metal ion catalysts was carried out in reactor-A (Figures 2 and 3). For these experiments, $750 \mathrm{ml}$ of $0.0005 \mathrm{M}$ unbuffered aqueous solution of the nitrophenol was taken in the reactor. The initial $\mathrm{pH}$ was adjusted at 4.5 using dilute $\mathrm{H}_{2} \mathrm{SO}_{4}$ for homogeneous catalytic ozonation. The immersion tube containing the UV lamp was introduced into the photo reactor (reactor-A) (Figures 2 and 3 ). The reactor was covered with aluminium foil to protect the eyes from the brightness of UV radiation. The entire reactor set-up was mounted on a magnetic stirrer which provided uniform mixing of the reactor contents and effective dissipation of the heat energy produced during the course of reaction (Experiments done minimum twice).

Estimating the concentration of organic pollutants, nitrophenols: The spectrophotometric technique offers an easy, reliable and faster method for the determination of concentration of substrates studied in the present investigation since they showed a very strong absorption bands in UV range and obeyed the Beer's law.

$$
\mathrm{A}=\varepsilon \mathrm{cl}
$$

Where $\mathrm{A}$ is the absorbance, 1 the distance in the environment (optical path) $[\mathrm{cm}], \varepsilon$ the extinction coefficient $\left(\mathrm{M}^{-1} \cdot \mathrm{cm}^{-1}\right)$ and $\mathrm{c}$ is the concentration $[\mathrm{M}]$ of component.

The pollutant used in the present work had very strong absorption band and had a high molar extinction coefficient values $(\varepsilon)$ (Table 1). This naturally served as a very simple, reliable and rapid method for analysing the ascorbate concentration in water.

\section{Results and Discussion}

The aims and objectives of the presented work are of both academic and practical importance, as ever increasing amount of organic pollutants are finding their way into surface and ground water bodies, leading to serious pollution problems.

The present day need of developing countries for cost effective clean-up technologies and use of non-conventional energy sources for the same should see more such studies being taken up at the pilot scale. These results are expected to be useful in the designing of ozone oxidation systems to be applied for industrial wastewater treatment, with the future prospect of reuse and recycle of the wastewater.

The overall efficiency of the oxidative degradation of substrates is dependent on various process parameters such as initial pollutant concentration, nature of oxidant, $\mathrm{pH}$, temperature and presence of catalyst. In the present study, initial pollutant concentration and temperature are kept constant.

\begin{tabular}{|c|c|c|}
\hline Compound & $\boldsymbol{\lambda}_{\text {max }}(\mathbf{n m})$ & $\boldsymbol{\varepsilon}$ (litre/mole) \\
\hline o-nitrophenol & 279 & 3738.2 \\
m-nitrophenol & 272 & 5613.8 \\
p-nitrophenol & 320 & 8050.2 \\
\hline
\end{tabular}

Table 1: $\lambda_{\max }$ and $\varepsilon$ values of nitrophenols.

\section{Kinetics of the process}

The concentration decay profiles give a good idea of order of reaction and in order to evaluate the same for oxidation of nitrophenols, the experimental data obtained were fitted into the following rate expressions:

$$
-\mathrm{d}[\mathrm{C}] / \mathrm{dt}=\mathrm{k}[\mathrm{C}]^{\mathrm{n}}
$$

For a zero order reaction, Eqn. (14) becomes,

$$
[\mathrm{C}]=[\mathrm{C}]_{\mathrm{o}}-\mathrm{k}_{\mathrm{o}} \mathrm{t}
$$

Here, $[\mathrm{C}]_{0}$ and $[\mathrm{C}]$ are the initial substrate concentration and concentration at any time $\mathrm{t}$ respectively, and $\mathrm{k}_{\mathrm{o}}\left(\mathrm{M}_{\mathrm{min}} \mathrm{mi}^{-1}\right)$ is the rate constant. For a first order reaction the integrated form of Eqn. (14) becomes,

$$
\ln \left\{[\mathrm{C}] /[\mathrm{C}]_{\mathrm{o}}\right\}=-\mathrm{k}_{1} \mathrm{t}
$$

Where, first order rate constant is $\mathrm{k}_{1}\left(\mathrm{~min}^{-1}\right)$.

A plot of $\left\{[C]_{0}-[C]\right\}$ against time should be linear for a zero ${ }^{\text {th }}$ order reaction and the plot of $\ln \left\{[\mathrm{C}] /[\mathrm{C}]_{0}\right\}$ against time will be linear if first order kinetics is operative.

The overall pollutant degradation rate expression is written as:

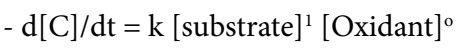

\section{Catalytic ozonation}

Due to a variety of catalysts used, it is suggested that both direct ozone reactions as well as decomposition of ozone with formation of hydroxyl radicals can occur. The catalytic ozonation studied in this work can be categorised as (i) Homogeneous catalytic ozonation using metal ion catalysts and (ii) Heterogeneous catalytic ozonation using granular activated carbon catalyst.

\section{Homogeneous catalytic ozonation}

In order to evaluate the catalytic influence of transition metal ions namely $\mathrm{Fe}^{2+}, \mathrm{Cu}^{2+}, \mathrm{Ce}^{4+}, \mathrm{Co}^{2+}$ and $\mathrm{Cr}^{3+}$ on photo-ozonation of nitrophenols, experiments were carried out in batch reactor $\mathrm{B}$. The catalyst was added in the form of its salt solution. Figures 4 and 5 explain the concentration decay curve. Tables 2 and 3 summarize the studies conducted using various metal ions as catalysts. From Table 3 and Figure 6 we can conclude that the decomposition of o-nitrophenol follows first order kinetics.

Contrary to the literature reports stating that the presence of transition metals $\mathrm{Fe}^{2+}, \mathrm{Cd}^{2+}, \mathrm{Cu}^{2+}, \mathrm{Zn}^{2+}, \mathrm{Co}^{2+}$ and $\mathrm{Cr}^{2+}$ affected the efficiency of ozonation process for degradation of phenols adversely, the present study reveals that $\mathrm{Cr}^{3+}, \mathrm{Co}^{2+}, \mathrm{Ce}^{4+}$ and $\mathrm{Cu}^{2+}$ ions favour the ozonation process by increasing the rate of ozonation and a much higher degradation of substrates was obtained in a given time [27]. However, $\mathrm{Fe}^{2+}$ and $\mathrm{Fe}^{3+}$ ions decreased the rate of degradation of nitrophenols indicating that they act as a negative catalyst. This can be attributed to the formation of a stable organometallic complex of ferrous ion with phenolic pollutants [20].

\section{Heterogeneous catalytic ozonation}

Granular activated carbon is the heterogeneous catalyst under study. GAC primarily works as an adsorbent in the waste-water treatment applications. To evaluate the extent of GAC adsorption in the present system, several test runs were performed using different doses of GAC. The efficiency of the GAC as catalyst can be comprehended by comparing simple ozonation process with ozonation in the presence of GAC as catalyst. 


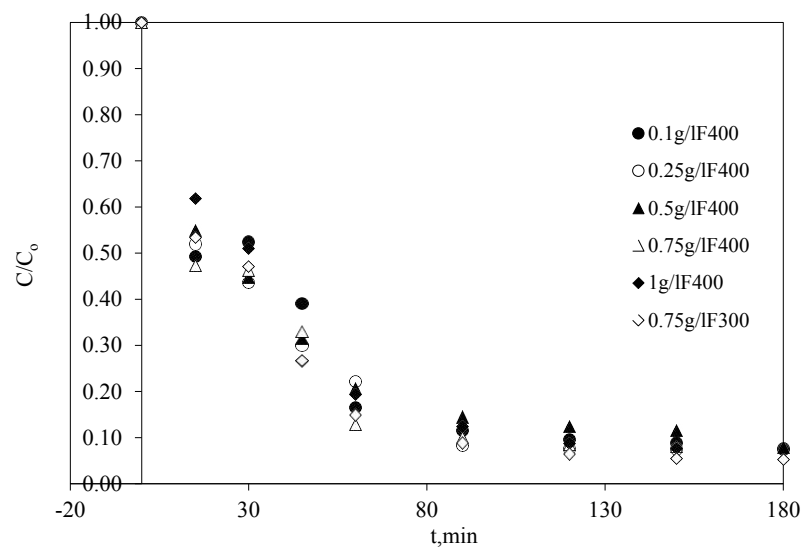

Figure 4: Concentration decrease of ONP as a function of time.

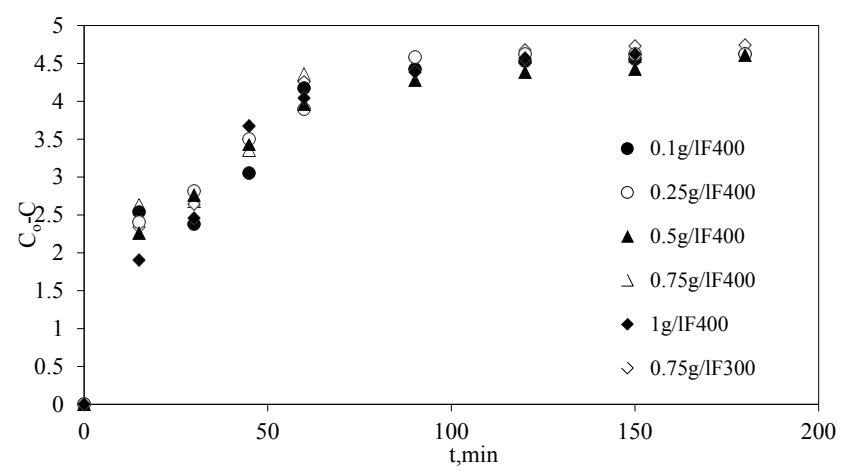

Figure 5: Concentration decrease of ONP as a function of time.

\begin{tabular}{|c|c|c|c|c|c|c|}
\hline No & Substrate & $\mathbf{M}^{\mathrm{n}^{+}}$ & 1 hour & 2 hour & 3 hour & 4 hour \\
\hline \multirow{5}{*}{1.} & \multirow{5}{*}{ o-Nitrophenol } & $\mathrm{Cr}^{3+}$ & $86.59 \%$ & $91.45 \%$ & $92.62 \%$ & $92.62 \%$ \\
\hline & & $\mathrm{Co}^{2+}$ & $91.66 \%$ & $93.75 \%$ & $93.75 \%$ & $93.75 \%$ \\
\hline & & $\mathrm{Cu}^{2+}$ & $89.63 \%$ & $92.14 \%$ & $92.14 \%$ & $92.14 \%$ \\
\hline & & $\mathrm{Ce}^{4+}$ & $88.46 \%$ & $90.81 \%$ & $91.77 \%$ & $91.77 \%$ \\
\hline & & $\mathrm{Fe}^{2+}$ & $49.01 \%$ & $57.40 \%$ & $60.13 \%$ & $65.69 \%$ \\
\hline \multirow{5}{*}{2.} & \multirow{5}{*}{ m-Nitrophenol } & $\mathrm{Cr}^{3+}$ & $74.23 \%$ & $87.86 \%$ & $91.74 \%$ & $92.45 \%$ \\
\hline & & $\mathrm{Co}^{2+}$ & $74.23 \%$ & $86.97 \%$ & $93.56 \%$ & $98.68 \%$ \\
\hline & & $\mathrm{Cu}^{2+}$ & $69.10 \%$ & $84.63 \%$ & $92.17 \%$ & $92.17 \%$ \\
\hline & & $\mathrm{Ce}^{4+}$ & $65.41 \%$ & $84.91 \%$ & $97.62 \%$ & $89.46 \%$ \\
\hline & & $\mathrm{Fe}^{2+}$ & $35.40 \%$ & $60.28 \%$ & $64.45 \%$ & $67.68 \%$ \\
\hline \multirow{5}{*}{6.} & \multirow{5}{*}{ p-Nitrophenol } & $\mathrm{Cr}^{3+}$ & $93.95 \%$ & $97.62 \%$ & $97.62 \%$ & $97.62 \%$ \\
\hline & & $\mathrm{Co}^{2+}$ & $94.64 \%$ & $97.99 \%$ & $97.99 \%$ & $97.99 \%$ \\
\hline & & $\mathrm{Cu}^{2+}$ & $91.04 \%$ & $97.25 \%$ & $99.80 \%$ & $99.80 \%$ \\
\hline & & $\mathrm{Ce}^{4+}$ & $86.40 \%$ & $91.88 \%$ & $96.00 \%$ & $99.55 \%$ \\
\hline & & $\mathrm{Fe}^{2+}$ & $43.11 \%$ & $61.13 \%$ & $79.54 \%$ & $89.55 \%$ \\
\hline
\end{tabular}

Table 2: \% Reduction of substrates concentration with various metal ion catalyst.

\begin{tabular}{|c|c|c|c|c|}
\hline Substrate & $\mathbf{M}^{\text {n+ }}$ & $\mathbf{K}$ & $\mathbf{R}^{\mathbf{2}}$ & $\mathbf{R}$ \\
\hline \multirow{4}{*}{ o-Nitrophenol } & $\mathrm{Cr}^{3+}$ & $\mathrm{k}_{1}=0.0184$ & 0.9661 & 09829 \\
\cline { 2 - 5 } & $\mathrm{Co}^{2+}$ & $\mathrm{k}_{1}=0.0258$ & 0.9444 & 0.9718 \\
\cline { 2 - 5 } & $\mathrm{Cu}^{2+}$ & $\mathrm{k}_{1}=0.0281$ & 0.9897 & 0.9948 \\
\cline { 2 - 5 } & $\mathrm{Ce}^{4+}$ & $\mathrm{k}_{1}=0.0181$ & 0.9737 & 0.9868 \\
\cline { 2 - 5 } & $\mathrm{Fe}^{2+}$ & $\mathrm{k}_{1}=0.0052$ & 0.9663 & 0.9830 \\
\hline
\end{tabular}

Table 3: Rate constant of reaction and regression coefficient values for homogeneous catalytic ozonation
In a normal oxidation process, the pollutants in the wastewater are specifically decomposed by coupling with oxygen. In the present GAC catalyzed process, the activated carbon catalyst acts as a catalyst as well as an adsorbent. The diagrammatic representation given below visibly demonstrates this point with ozonation and catalytic oxidation occurring at various stages of the combined treatment process. Consequently, the kinetics of pollutant destruction could be quite intricate for this case. In fact, attempts were made to fit the information acquired in the present study with kinetics of first and general order. Rather, in light of the conceivable switch over of adsorption and ozonation mechanisms at different phases of the combined treatment process, the kinetic mechanism can be given as; in the above mechanism, the pollutants (A) can be directly oxidized by ozonation in the liquid phase to end products $(C)$ in the treatment process or they could be adsorbed onto the GAC surfaces through the adsorption route to $\mathrm{B}$. The adsorbed pollutants are then catalytically oxidized on the GAC surfaces to end products $(\mathrm{C})$ which then get desorbed from the GAC surfaces to the aqueous phase. Tables 4 and 5 and Figure 7 prove that ozonation using GAC as catalyst is the best among the AOPs studied. The percentage degradation of the substrate studied was maximum using this process, as well as the time taken to achieve the target was minimum in this process as can be seen in Figures 8 and 9. Likewise, the heterogeneous catalytic ozonation of o-nitrophenol utilizing GAC follows first order kinetics (Figures 10 and 11).

\begin{tabular}{|c|c|c|c|c|c|}
\hline Substrate & GAC, $\mathbf{g L}^{-1}$ & 1 hour & 2 hour & 3 hour & 4 hour \\
\hline \multirow{6}{*}{ o-Nitrophenol } & $F-400,0.10$ & $83.49 \%$ & $90.43 \%$ & $92.46 \%$ & $92.46 \%$ \\
\hline & F-400, 0.25 & $77.87 \%$ & $92.46 \%$ & $92.46 \%$ & $92.46 \%$ \\
\hline & $F-400,0.50$ & $79.32 \%$ & $87.60 \%$ & $92.09 \%$ & $92.09 \%$ \\
\hline & F-400, 0.75 & $87.17 \%$ & $91.45 \%$ & $91.86 \%$ & $91.86 \%$ \\
\hline & $F-400,1.00$ & $80.17 \%$ & $91.29 \%$ & $92.41 \%$ & $91.41 \%$ \\
\hline & $F-300,0.75$ & $85.15 \%$ & $93.53 \%$ & $93.76 \%$ & $94.76 \%$ \\
\hline
\end{tabular}

Table 4: \% reduction of substrates concentration at various GAC doses.

\begin{tabular}{|c|c|c|c|c|}
\hline Substrate & $\mathbf{G A C}, \mathbf{g L}^{-1}$ & $\mathbf{k}$ & $\mathbf{R}^{2}$ & $\mathbf{R}$ \\
\hline & $\mathrm{F}-400,0.10$ & $\mathrm{k}_{1}=0.0178$ & 0.9707 & 0.9852 \\
\cline { 2 - 5 } & $\mathrm{F}-400,0.25$ & $\mathrm{k}_{1}=0.0271$ & 0.9782 & 0.9890 \\
\cline { 2 - 5 } & $\mathrm{F}-400,0.50$ & $\mathrm{k}_{1}=0.0144$ & 0.9659 & 0.9828 \\
\cline { 2 - 5 } o-Nitrophenol & $\mathrm{F}-400,0.75$ & $\mathrm{k}_{1}=0.0212$ & 0.9847 & 0.9923 \\
\cline { 2 - 5 } & $\mathrm{F}-400,1.00$ & $\mathrm{k}_{1}=0.0216$ & 0.9517 & 0.9756 \\
\cline { 2 - 5 } & $\mathrm{F}-300,0.75$ & $\mathrm{k}_{1}=0.0239$ & 0.9646 & 0.9821 \\
\hline
\end{tabular}

Table 5: Rate constant of reaction and regression coefficient values fo heterogeneous catalytic ozonation.

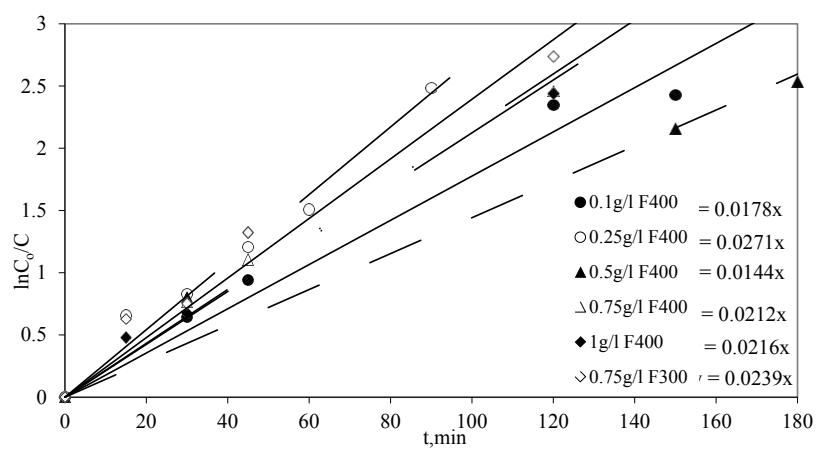

Figure 6: Concentration decrease of ONP as a function of time. 


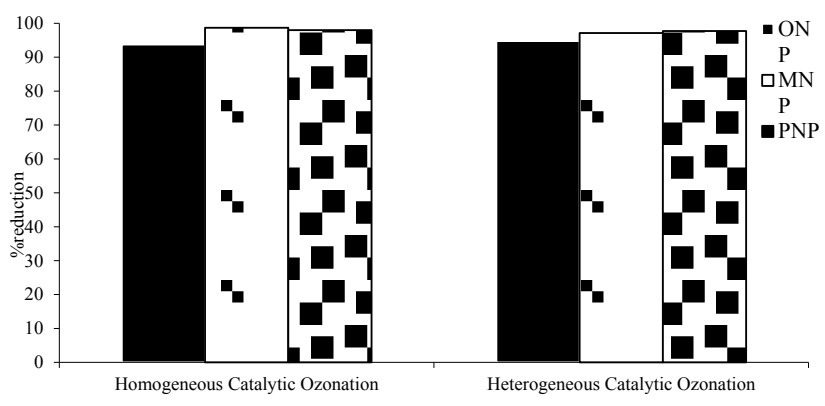

Figure 7: Bar diagram showing rate of degradation of nitrophenols.

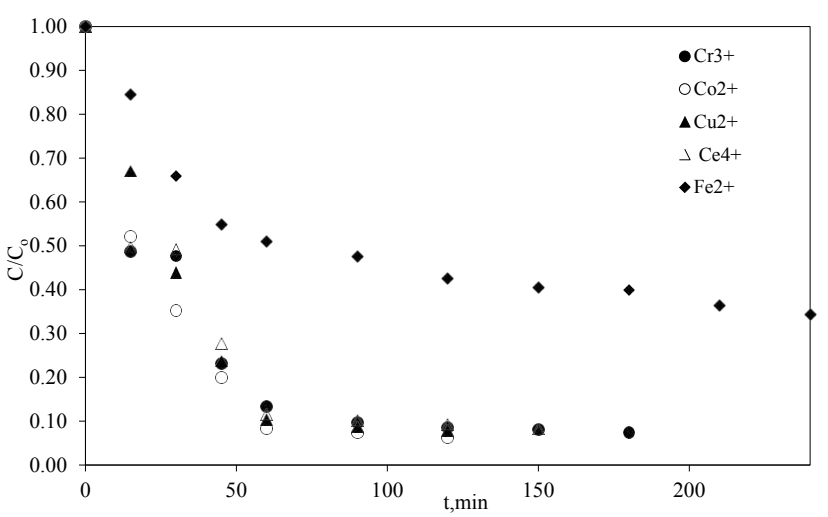

Figure 8: Concentration decrease of ONP as a function of time.

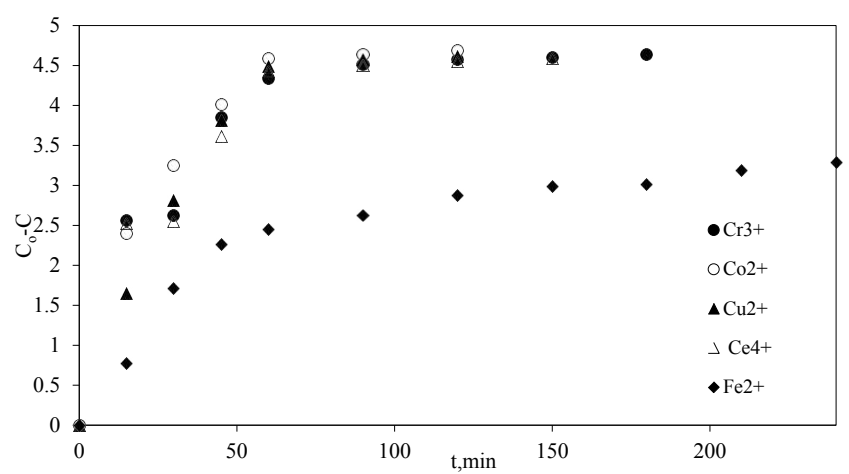

Figure 9: Concentration decrease of ONP as a function of time

Direct Oxidation

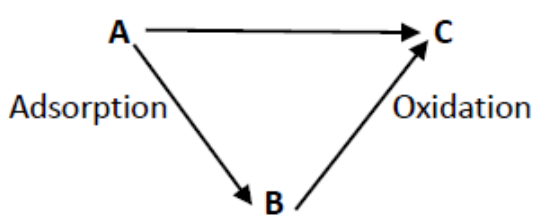

Figure 11: Diagrammatic representation of catalytic ozonation.

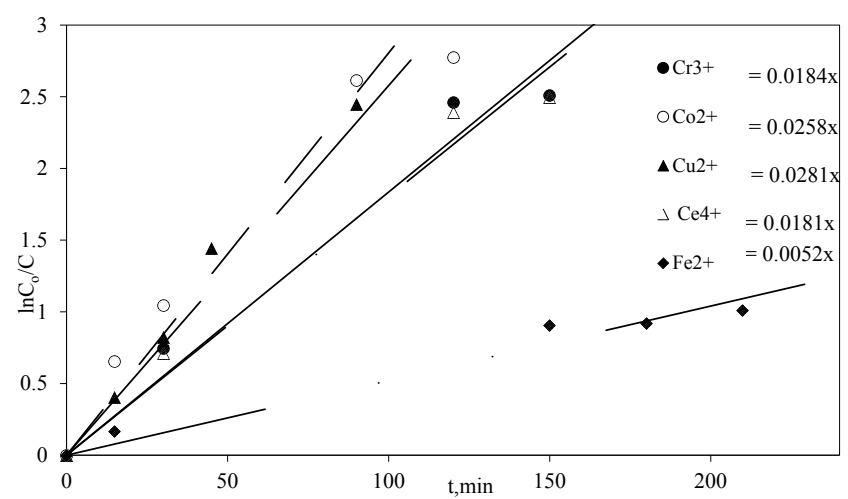

Figure 10: Concentration decrease of ONP as a function of time.

\section{Conclusions}

- These studies show that transition elements, namely $\mathrm{Cu}^{2+}, \mathrm{Co}^{2+}$, $\mathrm{Cr}^{3+}$ and $\mathrm{Ce}^{4+}$ ions, catalyse the ozonation process. Though $\mathrm{Fe}^{2+}$ ions inhibit the rate of ozonation, as they have a tendency to undergo complex formation with phenolic contaminants.

- Catalytic ozonation processes turn out to be proper techniques to competently expel nitrophenols from aqueous solutions. The catalysts $\mathrm{Co}^{2+}$ and $\mathrm{GAC}$ gave the best results with regard to reaction time and percentage degradation.

- In the case of heterogeneous catalytic ozonation occurs using GAC catalyst, it was found that first the pollutants were adsorbed as the solution concentration decreased significantly within 5 minutes of contact. From that point, the substrate was oxidized and ozonation turned into a dominating factor in the treatment procedure. The used up GAC was found to be recovered in situ.

- Systems utilizing substituted phenols with $-\mathrm{NO}_{2}$ substituents at the positions ortho-, meta- and para- were carried out to study the directing effect on the degradability. It is found that the substituent positions do control the oxidation process, especially in case of nitro phenols. In these compounds the para substituted derivative was observed to be effortlessly degraded at a higher rate.

\section{References}

1. Kamali M, Khodaparast Z (2015) Review on recent development on pulp and paper mill wastewater treatment. Ecotoxicology and Environmental Safety 114 326-342.

2. Ashrafi O, Yerushalmi L, Haghighat $F$ (2015) Wastewater treatment in the pulp-and-paper industry: A review of treatment processes and the associated greenhouse gas emission. J Environ Manag 158: 146-157.

3. Sanchez-Polo M, E. Rivera-Utrilla SJ, von Gunten U (2006) Combination of Ozone with Activated Carbon as an Alternative to Conventional Advanced Oxidation Processes. Ozone Sci Eng 28: 237-245.

4. Kaptijn JP, Plugge MFC, Annee JHJ (1995) Proceedings of the 12th Ozone World Congress, IOA, Lille, France, pp: 15-18.

5. Kaptijn JP (1997) Ecoclear process Results from full scale installations. Ozone Sci Eng 19: 297-305

6. Logemann FP, Annee JHJ (1997) Water treatment with a fixed bed catalytic ozonation process. Water Sci Tech 35: 353-360.

7. Delanoe F, Acedo B, Leitner NKV, Legube B (2001) Relationship between the structure of $\mathrm{Ru} / \mathrm{CeO}_{2}$ catalysts and their activity in the catalytic ozonation of succinic acid aqueous solutions. Appl Catal B 29: 315-325. 
Citation: Shanthi S (2017) Catalytic Ozonation: An Advanced Strategy for the Removal of Nitro Phenols from Contaminated Water. J Adv Chem Eng 7: 168. doi: 10.4172/2090-4568.1000168

8. Jans U, Hoigne J (1998) Activated carbon and carbon black catalysed transformation of aqueous ozone into $\mathrm{OH}$ radicals. Ozone Sci Eng 20: 67.

9. Shanthi S, Yenkie MKN (2016) P-Nitrophenol: A Model Compound for the Study of Role of PH in the Reaction of Ozone with Phenols. J Pollut Eff Cont 4: 168.

10. Yuan-Xiang Yao, He-Bing Li, Jin-Yun Liu, Xin-Liang Tan, Jin-Gang Yu, et al. (2014) Removal and Adsorption of p-Nitrophenol from Aqueous Solutions Using Carbon Nanotubes and Their Composites. J Nanomaterial 2014: 571745.

11. Yao J, Huang Z, Masten SJ (1998) The ozonation of pyrene: pathway and product identification. Water Res 32: 3001-3012.

12. Drzewicz P, Trojanowicz M, Zona R, Solar S, Gehringer P (2004) Decomposition of 2,4-dichlorophenoxyacetic acid by ozonation, ionizing radiation as well as ozonation combined with ionizing radiation. Radiat Phys Chem 69: 281-287.

13. Dara SS (2002) A textbook of Environmental Chemistry and Pollution control S.Chand \& Company Ltd., New Delhi, pp: 65-109.

14. Fontanier V, Farines V, Albet J, Baig S, Molinier J (2003) Catalytic ozonation for mineralization of organic compounds. IOA: International Conference on Ozone and Related Technologies-Processes in Global Water Sanitation, Proceedings, Berlin, Germany, pp: 501-515.

15. Ma J, Graham NJD (1999) Degradation of atrazine by manganese- catalysed ozonation: influence of humic substances. Water Res 33: 785-793.

16. Volk C, Roche P, Joret JC, Paillard H (1997) Comparison of the effect of ozone, ozone-hydrogen peroxide system and catalytic ozone on the biodegradable organic matter of a fulvic acid solution. Water Res. 31: 650-656.

17. Cortes S, Sarasa J, Ormad P, Gracia R, Ovelleiro JL (1998) Comparative efficiency of the systems $\mathrm{O}_{3} /$ high $\mathrm{pH}$ and $\mathrm{O}_{3} /$ catalyst for the oxidation of chlorobenzenes in water. IOA: International Regional Conference, Proceedings, Poitiers, France, 14: 14.

18. Cooper C, Burch R (1998) An investigation of catalytic ozonation for the oxidation of halocarbons in drinking water preparation. Water Res 33: 36953700 .

19. Baig S, Petitpain F (2003) Catalytic ozonation for advanced treatment of industrial wastewater. IOA: International Conference on Ozone and Related Technologies Processes in Global Water Sanitation, Proceedings, Berlin, Germany, pp: 217-229.

20. Gracia R, Aragues JL, Cortes S, Ovelleiro JL (1995) Proceedings of the 12th World Congress of the International Ozone Association, Lille, France, pp: 75.

21. Pereira MFR, Goncalves AG, Orfao JJM (2014) Carbon materials as catalysts for the ozonation of organic pollutants in water Bol. Grupo Espanol Carbon 31: 18-24.

22. Beltran FJ, Rivas J, Alvarez P, Montero-de-Espinosa R (2002) Kinetics of heterogeneous catalytic ozone decomposition in water on an activated carbon. Ozone Sci Eng 24: 227-237.

23. Enjarlis E, Ratnawati R (2011) Kinetics and Identification of Products Degradation of Endosulfan in a Solution of Carbofuran by Hydrolysis, Ozonation with and Without Activated Carbon. Int J Cheml Eng Appl 2: 42-46.

24. Pinker B, Henderson WD (1996) The effect of ozonation on the performance of GAC. In Proc Reg Conf Ozone, UV-light, AOPs Water Treatm, Amsterdam, Netherlands, pp: 307-318.

25. ATSDR (Agency for Toxic Substances and Disease Registry) (1992) Toxicological profile for NPs. Department of Health and Human Services Public Health Service, Atlanta, GA, US.

26. Keith LN, Telliard WA (1979) Priority pollutants. 1 - A perspective view. Environ Sci Technol 13: 416-423.

27. Masschelein WJ, Goossens R (1984) Nitrophenols as model compounds in the design of ozone contacting and reacting systems. Ozone Sci Eng 6: 143-162. 